\title{
Resilience in Nursing Students: The Effect of Academic Stress and Social Support
}

\author{
Aysel Ozsaban ${ }^{1}$ (D) Nuray $\operatorname{Turan}^{1}{ }^{(\mathbb{D}}$, Hatice Kaya ${ }^{1}$ \\ ${ }^{1}$ Istanbul University-Cerrahpaşa, Florence Nightingale Nursing Faculty, Department of Fundamentals of Nursing, Istanbul, Turkey \\ Correspondence Author: Nuray Turan \\ E-mail: nkaraman@istanbul.edu.tr \\ Received: $01.02 .2017 \quad$ Accepted: 10.04 .2017
}

\begin{abstract}
Objective: This study was conducted to evaluate the levels of psychological resilience, academic stress and social support available to nursing students and the relationship between these factors.

Methods: The population of the study, which had a descriptive and correlational research design, was made up of 1202 students, while the sample consisted of 322 students selected using the sample size formula for a known population. Data were collected using a Structured Questionnaire, the Psychological Resilience Scale for Adults, the Nursing Education Stress Scale and the Multidimensional Scale of Perceived Social Support.

Results: $76.7 \%$ of students were female and $23.3 \%$ were male. A statistically significant correlation was found between scores for psychological resilience and perceived social support $(p<0.05)$. It was found that the individual characteristics of students affected their psychological resilience. Levels of psychological resilience, academic stress, and social support among nursing students are at a moderate level.

Conclusion: The significance of resilience is clear, a better understanding is needed of what factors affect a student's level of resilience and how this resilience can best be improved.
\end{abstract}

Keywords: Resilience, academic stress, social support, nursing students

\section{INTRODUCTION}

Individuals generally encounter a number of challenges and problems over the course of their lives; these can range from day-to-day issues to specific crises or other events. Managing individuals' environment carefully to help them overcome any adversities is of vital importance (1). Some professionals employed in highly stressful situations are particularly at risk of suffering problems such as depression, anxiety, burnout and traumatic stress. One occupational group particularly vulnerable to high levels of stress at work are those working in health care (2).

Nurses in particular work in tense and demanding environments. They often experience conditions that are far from optimal (including lengthy or unpredictable hours) and these can increase their psychological vulnerability (3). During nursing education, nursing students can also be under stress as they attempt to deploy the new ideas and skills they have learned in a practical setting. As nursing students experience higher levels of stress than students in other health subjects it is essential to understand how their degree of resilience affects them (4).

Psychological resilience can be viewed as a multi-dimensional construct and it is critical that is clearly defined in order to differentiate it from related constructs, some of which may have overlapping meanings (2). Psychological resilience can be defined as a person's capacity to adapt and cope in the face of difficult situations $(5,6,7)$. Psychological resilience is a complicated and dynamic process that is affected by biophysiological, psychological, socio-cultural and politicoeconomic factors $(8,9)$. Psychological resilience is increased by becoming more healthy, improving the quality of life and developing and improving coping mechanisms $(6,7,10,11)$.

Improving psychological resilience and managing stressful situations are capacities that society at large expects from nurses. These qualities can be fostered in nursing students with the aid of the educational process and educational experience. Like every university student, nursing students will have various stress-oriented experiences $(7,12)$. However, worries concerning academic success remain one of the most important reasons for stress. Academic stress consists of the physical, mental and emotional responses that emerge because of the emotions and thoughts related to educational conflict, disappointment, pressure and the fear of being unsuccessful (13). It may have an impact on one's concentration, memory, and the processes making decisions and solving problems. As a result of this, it may also affect the level of academic success and resilience of nursing students. Increasing academic success and adapting 
to changing situations require effective stress management and the use of various coping mechanisms $(12,14)$.

Studies about protecting and improving the resilience of nursing students have reported that social support plays a significant role. The perception of social support is associated with an individual's appraisal of their value. An individual who thinks that they are loved, valued, helped when needed, and that their relationships are satisfying, perceives themself as more supported. Social support systems have an important role in decreasing or balancing the damage caused by the stressful situations that individuals face $(10,15,16)$. Studies note that one's perception of social support is related to the level of resilience felt and demonstrated (17-19).

In this context, it can be asserted that the concept of nursing students' resilience is important, that it is directly related to academic success and that it affects their coping mechanisms. However, there is limited research on this subject. Within this context, there is a clear need for studies aimed at determining the factors that affect resilience and that create strategies to improve it (20-22).

The aim of this study was to evaluate levels of psychological resilience, academic stress and social support among nursing students and determine the relationships between them. The research questions were as follows:

- What are the nursing students' psychological resilience levels?

- What are the nursing students' academic stress levels?

- What are the nursing students' social support levels?

- Is there any relationship between the nursing students' levels of resilience, academic stress and social support?

- Which factors affect levels of psychological resilience, academic stress and social support in nursing students?

\section{METHODS}

\subsection{Design and Participants}

This study used a descriptive and correlational research design. The population of the study was made up 1202 students studying in 2015-2016 academic year at the Istanbul University, Florence Nightingale Nursing Faculty, while the sample of study included 322 students selected using the sample size formula for a known population. Sampling was conducted by a stratified random sampling method. The stratification criteria were the classes which the subjects taking part were attending. Potential participants were selected and assigned at random by researchers from a table constructed of random numbers. The inclusion criteria was that students were willing to participated and did so voluntarily.

\subsection{Data collection}

Researchers collected data via one-on-one interviews. Investigators met with the students and explained the aim and scope of the study, its duration and what was expected of the participants. In the data collection, a Structured Questionnaire Form, the Psychological Resilience Scale for Adults and the Nursing Education Stress Scale were used.

Structured Questionnaire Form: The questionnaire form was prepared by considering studies related to the literature $(10,12,16)$. The form contains variables of gender, age, year of education, income, average success, marital status, number of siblings, working status, living area and health insurance.

Psychological Resilience Scale for Adults: The scale was developed by Friborg et al. to measure the level of adults' psychological resilience and a six-dimensional structure was then created by the same researchers in 2005 . The scale has a total of 33 items with 6 dimensions including "structural style" and "perception of future " with 4 items each, "family cohesion", "perception of self" and "social competence" with 6 items each and "social resources" with 7 items. The Cronbach alpha internal consistency coefficient was found to be 0.86 in the Turkish version of the study conducted by Basım and Çetin in 2011 (9). A format was used in which positive and negative attributes were on different sides, and for answers, five separate options were given in order to avoid prejudiced evaluations of preference for items of scale. A score of 1 to 5 was accepted as showing that psychological resistance increased as the score increased. Questions 1, 3, 4, 8, 11, 12, 13, 14, 15, 16, 23, 24,25, 27, 31 and 33 in the scale were accepted as inverse questions and scored accordingly.

Nursing Education Stress Scale: The scale was modified and developed by Rhead from the Nurse Stress Scale developed by Gray-Toft and Anderson. Karaca et al. conducted a Turkish validity and reliability study in 2014 (23). The scale is made up of two sub-dimensions and 32 items and is a quadratic (0-3 points) Likert type. For the "practice stress" sub-dimension, questions 4, 5, 7, 9, 11, 13, 15, 16, 18, 19, 21, 24, 25, 27, 29 and 32 are used; for the "academic stress" sub-dimension, questions 1, 2, 3, 6, 8, 10, 12, 14, 17, 20, 22, 23, 26, 28, 30 and 31 are used. Each subscale has a value from 0 to 48 and the total score obtainable from the scale is between 0 and 96. An increase in score indicates an increasing level of stress. Since the Cronbach's alpha values of the scale items are higher than 0.83 , the internal consistency is high and the scale is reliable.

Multidimensional Scale of Perceived Social Support: This was developed in 1988 by Zimet and his colleagues. The validity and reliability studies in Turkey were carried by Eker and Arkar in 1995 (24). The scale is a Likert type instrument arranged in a range from 1 to 7 , from "absolutely no" (1) to "absolutely yes" (7). There are three subgroups: "family", "friend" and "someone special" which reflect the support resources given in the scale. Each group consists of 4 items, and there is a total of 12 items. Support from family is measured by items $3,4,8$ and 11 on the scale, support from friends is measured by items $6,7,9$ and 12, and items 1, 2, 5 and 10 measure the support from a partner or someone very close. A high score on the scale indicates that perceived social support is high. 
The internal consistency Cronbach alpha values are 0.85 for the "family" subscale, 0.88 for the "friend" subscale and 0.92 for the "someone special" subscale.

\subsection{Ethical Considerations}

Ethical approval for this study was granted by the Istanbul University Ethics Committee (Date: 25.05.2016 Number: 112). The researchers explained the purpose of the research, roles of participants, benefits and potential risks of the study and their right to withdraw at any time. Students' written consents/approvals were received with Used Confidentiality Agreement Form.

\subsection{Research Limitations}

This study involved nursing students in only one nursing faculty. Therefore, the results cannot be generalized to all other nursing schools. The results might not be representative of the wider nursing student population.

\subsection{Statistical analysis}

Data were analysed using the Statistical Package for Social Sciences 22.0 (SPSS 22.0) using frequency, percentage, minimum, maximum, mean, standard deviation for descriptive analyses. Student t tests, the One way ANOVA test and Tukey HSD were used for comparison of the groups. The relationships between levels of psychological resilience, academic stress and perceived social support were analyzed using Pearson's Correlation Analysis. $\mathrm{p}<0.05$ was considered statistically significant.

\section{RESULTS}

\subsection{Students' socio-demographic characteristics}

The average age of the students was $20.65 \pm 1.65$. $76.7 \%$ $(n=247)$ of the students were female, and $23.3 \% \quad(n=75)$ were male. $32.6 \%(n=105)$ were sophomore students and their average academic success level was $2.70 \pm 0.41$ (in a 4 point grading system). $48.8 \%$ ( $n=157)$ lived with their families and $38.8 \%(n=125)$ had 2 siblings. $88.5 \%(n=285)$ were not employed, $74.8 \%(n=241)$ were self-employed and $86 \%$ $(n=277)$ had health insurance.

\subsection{Average total scores and sub-dimension scores for the Psychological Resilience Scale For Adults, the Nursing Education Stress Scale and the Multidimensional Scale of Perceived Social Support}

The average scores of the students for the Psychological Resilience Scale for Adults were as follows: 3.61 \pm 0.76 for "structural style", 3.79 \pm 0.85 for "perception of future", $3.77 \pm 0.77$ for "family cohesion", $3.71 \pm 0.69$ for "perception of self", $3.69 \pm 0.71$ for "social competence", and $4.01 \pm 0.67$ for "social resources". The average total score of the
Nursing Education Stress Scale was 63.84 \pm 16.83 ; for its subdimensions, it was found to be $32.17 \pm 8.81$ for "practice stress" and $31.66 \pm 8.86$ for "academic stress". The average total score for the Multidimensional Scale of Perceived Social Support was 65.16 \pm 14.08 ; for the sub-dimensions, it was $22.84 \pm 5.22$ for "family", $22.78 \pm 5.16$ for "friend", and $19.54 \pm 8.01$ for "someone special" (Table 1 ).

Table 1. Average total scores and sub-dimension scores of the Psychological Resilience Scale for Adults, Nursing Education Stress Scale and Multidimensional Scale of Perceived Social Support $(n=322)$

\begin{tabular}{|lll|l}
\hline Scale & Sub-dimension & Min.-Max. & Avg. \pm SD \\
\hline & Structural Style & $1-5$ & $3.61 \pm 0.76$ \\
Psychological & Perception of Future & $1-5$ & $3.79 \pm 0.85$ \\
Resilience Scale & Family Cohesion & $1.17-5$ & $3.77 \pm 0.77$ \\
for Adults & Self Perception & $1.67-5$ & $3.71 \pm 0.69$ \\
& Social Competence & $1.5-5$ & $3.69 \pm 0.71$ \\
& Social Resources & $2-5$ & $4.01 \pm 0.67$ \\
\hline Nursing & Practice Stress & $3-48$ & $32.17 \pm 8.81$ \\
Education Stress & Academic Stress & $3-48$ & $31.66 \pm 8.86$ \\
Scale & Total & $6-96$ & $63.84 \pm 16.83$ \\
\hline Multidimensional & Family & $4-28$ & $22.84 \pm 5.22$ \\
Scale of & Friend & $4-28$ & $22.78 \pm 5.16$ \\
Perceived Social & Someone Special & $4-28$ & $19.54 \pm 8.01$ \\
Support & Total & $18-84$ & $65.16 \pm 14.08$ \\
\hline
\end{tabular}

Min.:Minimum Max.:Maxsimum

Avg. Average, SD: Standartd Deviation

\subsection{Correlation of psychological resilience and academic stress}

No statistically significant correlation was found between the nursing students' average scores for the Psychological Resilience Scale for Adults and the Nursing Education Stress Scale and their sub-dimensions ( $p>0.05$; Table 2).

\subsection{Correlation of psychological resilience and perceived social support}

A statistically significant correlation was found between the scores for all the sub-dimensions of Psychological Resilience Scale for Adults and the "family" sub-dimension of the Multidimensional Scale of Perceived Social Support $(p<0.05)$. A significant correlation was found between the score for the "friend" sub-dimension of the Multidimensional Scale of Perceived Social Support, and the scores for "perception of future", "family cohesion", "perception of self", "social competence" and "social resources" sub-dimensions of the Psychological Resilience Scale for Adults $(p<0.05)$. A significant correlation was found between the "someone special" subdimension of the Multidimensional Scale of Perceived Social Support, and the scores for "perception of future" and "social resources" sub-dimensions ( $p<0.05$; Table 2$)$. 
Table 2. Correlation analyses of Psychological Resilience Scale for Adults and Nursing Education Stress Scale and Multidimensional Scale of Perceived Social Support $(n=322)$

\begin{tabular}{|c|c|c|c|c|c|c|c|c|c|c|c|c|c|}
\hline Scales & Sub-dimensions & \multicolumn{12}{|l|}{ Scales } \\
\hline & & \multicolumn{12}{|c|}{ Nursing Education Stress Scale } \\
\hline 言 & & \multicolumn{2}{|c|}{ Practice Stress } & \multicolumn{2}{|c|}{ Academic Stress } & \multicolumn{2}{|l|}{ Total } & \multicolumn{2}{|c|}{$\begin{array}{l}\text { Practice } \\
\text { Stress }\end{array}$} & \multicolumn{2}{|c|}{$\begin{array}{l}\text { Academic } \\
\text { Stress }\end{array}$} & \multicolumn{2}{|c|}{ Total } \\
\hline$\frac{0}{\pi}$ & & \multicolumn{2}{|l|}{ r } & \multicolumn{2}{|c|}{$\mathrm{p}$} & \multicolumn{2}{|l|}{$r$} & \multicolumn{2}{|c|}{$p$} & \multicolumn{2}{|l|}{$r$} & \multicolumn{2}{|l|}{$P$} \\
\hline జ & Structural Style & \multicolumn{2}{|l|}{0.035} & \multicolumn{2}{|c|}{0.535} & \multicolumn{2}{|c|}{-0.009} & \multicolumn{2}{|c|}{0.876} & \multicolumn{2}{|c|}{0.014} & \multicolumn{2}{|c|}{0.809} \\
\hline$\underline{\underline{\underline{v}}}$ & Perception of Future & \multicolumn{2}{|l|}{-0.041} & \multicolumn{2}{|c|}{0.462} & \multicolumn{2}{|c|}{-0.106} & \multicolumn{2}{|c|}{0.057} & \multicolumn{2}{|c|}{-0.077} & \multicolumn{2}{|c|}{0.166} \\
\hline$\stackrel{\dddot{q}}{\varpi}$ & Family Cohesion & \multicolumn{2}{|l|}{-0.036} & \multicolumn{2}{|c|}{0.522} & \multicolumn{2}{|c|}{-0.091} & \multicolumn{2}{|c|}{0.104} & -0.0 & & 0.23 & \\
\hline$\frac{\mathrm{O}}{\mathrm{d}}$ & Self Perception & -0.105 & & 0.0 & & -0.095 & & $0.08 \varepsilon$ & & -0.1 & & 0.06 & \\
\hline 응 & Social Competence & -0.011 & & 0.8 & & -0.066 & & 0.237 & & -0.0 & & 0.47 & \\
\hline ते & Social Resources & 0.093 & & 0.0 & & 0.024 & & 0.66 & & 0.0 & & 0.27 & \\
\hline & & Multid & sional Sca & le $c$ & erceive & ial Support & & & & & & & \\
\hline ప̄ & & Family & & & Friend & & Someo & one $S$ & & & Total & & \\
\hline$\frac{\omega}{\pi}$ & & r & $P$ & & r & $p$ & r & & $p$ & & r & & $p$ \\
\hline$\underline{\underline{w}}$ & Structural Style & 0.161 & $0.004^{* *}$ & & 0.099 & 0.075 & 0.065 & & 0.2 & & 0.134 & & $0.016^{*}$ \\
\hline & Perception of Future & 0.289 & $0.001^{* *}$ & & 0.252 & $0.001^{* *}$ & 0.125 & & 0.0 & & 0.271 & & $0.001^{* *}$ \\
\hline & Family Cohesion & 0.628 & $0.001^{* *}$ & & 0.458 & $0.001^{* *}$ & 0.105 & & 0.0 & & 0.460 & & $0.001^{* *}$ \\
\hline & Self Perception & 0.123 & $0.027^{*}$ & & 0.171 & $0.002^{* *}$ & 0.057 & & 0.3 & & 0.141 & & $0.011 *$ \\
\hline 은 혼 & Social Competence & 0.231 & $0.001^{* *}$ & & 0.360 & $0.001 * *$ & 0.094 & & 0.0 & & 0.271 & & $0.001^{* *}$ \\
\hline हे क्षे & Social Resources & 0.550 & $0.001^{* *}$ & & 0.556 & $0.001^{* *}$ & 0.166 & & 0.0 & & 0.502 & & $0.001^{* *}$ \\
\hline$\breve{m}$ & & Multid & sional Sca & le o & erceive & ial Support & & & & & & & \\
\hline ڤે & & Family & & & Friend & & Someo & one $S$ & cial & & Total & & \\
\hline 疋 & & $r$ & $P$ & & r & $p$ & $r$ & & $p$ & & r & & $p$ \\
\hline 굽 & Practice Stress & 0.036 & 0.515 & & 0.032 & 0.568 & -0.040 & & 0.4 & & 0.002 & & 0.964 \\
\hline : & Academic Stress & 0.005 & 0.931 & & -0.039 & 0.491 & -0.020 & & 0.7 & & -0.024 & & 0.670 \\
\hline ₹ & Total & 0.022 & 0.699 & & -0.004 & 0.949 & -0.032 & & 0.5 & & -0.011 & & 0.841 \\
\hline
\end{tabular}

\subsection{Correlation of nursing education stress and perceived social support}

No statistically significant correlation was found between the total scores and sub-dimensions of the Multidimensional Scale of Perceived Social Support and total scores of "practice stress" and "academic stress" sub-dimensions and the Nursing Education Stress Scale ( $p>0.05$; Table 2).

\subsection{Socio-demographic characteristics and psychological resilience levels}

The score for the Psychological Resilience Scale for Adults for 20 years-old and younger students was found to be significantly higher than the scores for the "family cohesion" and "social resources" subscales ( $p<0.01)$. The average scores of women for the sub-dimensions of the Psychological Resilience Scale for Adults were higher than that of men at a statistically significant level $(p<0.05)$. The average scores of sophomore students in the Social Resources and Family Cohesion sub-dimensions of Psychological Resilience Scale for Adults are higher than that of students in other classes and this difference was statistically significant $(p<0.05)$. There was no significant difference between the resilience levels of the individuals that had nuclear families or extended families ( $p>0.05)$. The mean score for the "structural style" subscale scores of those who had four or more siblings was significantly higher than the others $(p<0.05)$. The mean score for the "social sufficiency" subscale of individuals who had 2 siblings or fewer was found to be statistically significantly higher than those had four siblings or more ( $p$ $<0.01)$. The mean score for the "social resource" subscale of those whose income matched their expenditure was found to be statistically significantly higher than those who could not meet their expenses ( $p<0.01)$. The "social assistance" subscale mean score of those with social security was found to be statistically significantly higher than those without social security $(p<0.05)$. The mean score for the "family cohesion", "social qualification" and "social resources" subscales of the unemployed were found to be statistically significantly higher than those who were employed ( $p<0.01$, Table 3 ). 
Table 3. Comparison of socio-demographic characteristics and sub-dimension scores of Psychological Resilience Scale for Adults (n=322)

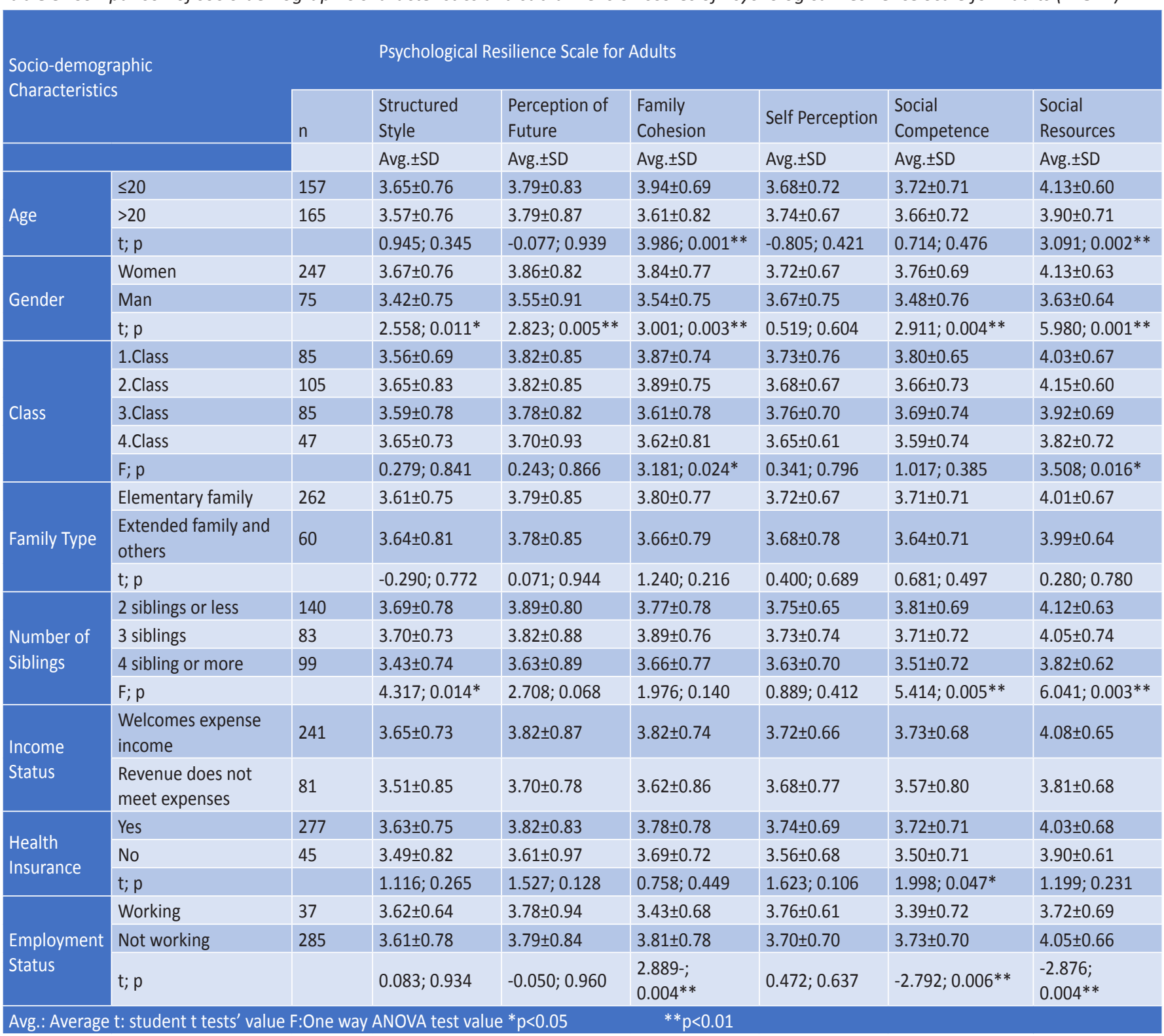

\section{DISCUSSION}

Nursing students have to cope with various stressors in both educational and the clinical environments. A high level of resistance is needed to be able to manage this and progress. Psychological resilience is an important factor affecting the academic life of nursing students. Learning to limit stress and developing psychological resilience in the clinical practice environment are important topics in helping students to gain new perspectives and to cope with stress during clinical practice $(20,24,25)$. This research was carried out to evaluate levels of psychological resilience of nursing students, explain the relationship of these to academic stress, which is thought to have an important effect on resilience, and also to examine the effect of social support, which is an external factor.

In this study, the scores obtained from the subscales of the Psychological Resilience Scale showed that the psychological resilience of the students was at medium level. In the research by Smith and Yang, and Rios-Risques et al., the resilience level of nursing students was also found to be moderate $(26,27)$. The finding obtained from this research was thus similar to other research findings. In this respect, it can be said that the psychological resilience of the students was not at a sufficient level and that it needs to be increased. Academics are an important resource for increasing the resilience level of students. Professional resilience should begin by developing acute care areas and educational strategies within nursing education and it should continue with postgraduate experience. New nurses may increase their level of resilience as they become familiar with the social environment of the clinic and develop their own skills, but they may also need more time to develop (28).

Stress in nursing education is a very controversial issue. Stress is an issue that can negatively affect the psychological 
and physiological health of students and their academic achievement. Students with high stress levels also have low levels of coping $(29,30)$. When the findings obtained from this research related to the academic stress experienced by students were examined, it was determined that the academic stress levels of the students were slightly above medium, and the academic and practice stress subscale scores were also similar and slightly above the moderate level. In Pines et al.'s study, the students' stress susceptibility scores were found to be around average as well (31). The stress levels of nursing students were higher in similar studies conducted in Turkey. In these studies, many internal and external factors which may cause stress, such as the assessment and examination system in Turkey, problems in clinical practice environments, the attitudes of educators and the individual characteristics of students were identified (32-34). Another study conducted with the aim of determining and comparing stress levels of nursing students in five countries showed that stress is a common problem for nursing students (35). In the light of these findings, there is a need to develop programs for strengthening students' ability to cope with stress, to provide university and clinical orientation, and to plan the initiatives necessary by examining each institution-specific stressor.

Social support is one of the most significant external factors having an impact on an individuals' capacity to handle stressful situations $(16,29,30)$. In this study, it was determined that the level of social support students perceived themselves to have was moderate, and the subscales of "family", "friends" and "someone special" were also found to be moderate and close to each other. Activities could be planned within a Faculty to increase the social support provided to students. For example, organizing social club activities to increase the level of support from friends will also increase the interaction of students with each other. Moreover, unlike the findings in the literature, in this study, there was no significant relationship between the stress level of students and level of perceived social support. It will be necessary to carry out repeated studies to explain the reasons for this finding.

There is a mutual and negative relationship between stress and resilience. Studies have shown that the resilience level of stressed individuals is low. In the study by Pines et al., it was found that students with higher scores for "psychological refreshment" had higher resilience scores (31). In this respect, it has been proposed that strategies be developed for the psychological strengthening of students. It has also been determined in research conducted with nursing students that the levels of resilience and academic success are negatively affected by academic stress $(20,21,29)$. Smith and Yang found a negative relationship between nursing students' resilience, stress and psychological well-being (27). However, in this study, a relationship was not found between resilience and the stress levels of students.

In this study, the level of resilience, social support the six dimensions of psychological resilience of the students were found to be significantly correlated. This finding supports the literature showing that the level of social support is higher for students that have a high level of psychological resilience $(20,29,36)$. Programs should aim increase the level of social support and thus to strengthen the resilience of students.

The research demonstrated that the socio-demographic characteristics of the students affected the resilience level. Age is an individual characteristic that affects psychological resilience and perceived stress level $(26,37)$. The mean score for the "family cohesion" and "social resources" scores of students aged 20 and under in this study was found to be significantly higher than that of those aged 20 and over. The lower "family cohesion" and "social resources" scores for younger people may be considered as a reflection of the socio-cultural characteristics of the society in which the students live.

In the research, the level of resilience demonstrated by female students was significantly higher than that of male students. This difference may be related to the fact that the social support level of female students was higher than that of male students (30). In a study conducted by Altıok and Üstün in Turkey, it was revealed that male students experienced different behaviors from other nurses and patients during clinical practice because they were male, and this was determined to be an important stressor (33). Male students participating in the research may have experienced more stress, which may have negatively affected their resilience levels.

As the students' amount of education increases, it is expected that the ability to cope with stressful situations will also increase. In a study on the psychological well-being and resilience of nursing students, it was determined that upper-class students experienced more psychological wellbeing than other students (27). In this study, the sophomore students were found to be stronger and have significantly greater social resources in the "family adjustment" subscales than the other students. In this context, initiatives to increase levels of social support may be useful for increasing levels of resilience.

In the study, the number of siblings, income status, access to social security and employment situation were also found to affect psychological resilience levels of students. However, family type did not affect resilience levels. Taking individual characteristics into account in efforts to increase the resilience of students will have an effect on the success of social and institutional support.

\section{CONCLUSION}

The levels of psychological resilience, stress and social support experienced by the students in the sample group were moderate. It is thus necessary to increase the students' levels of resilience. It is suggested that nurse educators and school administrators plan activities such as mentoring and group education sessions, and that they increase the number of social activities available and set clear organizational strategies. 
The resilience of nursing students needs to be strengthened, and their education needs to incorporate ways of doing this. Although the significance of resilience is clear, a better understanding is needed of which factors affect a student's level of resilience and how this resilience can best be improved. For this to happen, a more explicit definition of which resilience in nursing students involves should be formulated and applied in a consistent manner. This will allow better theoretical models to be developed and evaluated.

Conflict of Interest: The author's declare that they have no conflict of interest. There are no other potential conflicts of interest pertaining to this work.

Financial Disclosure: The authors declared that this study has received no financial support.

\section{REFERENCES}

[1] Fletcher D, Sarkar M. Psychological resilience a review and critique of definitions, concepts, and theory. Eur Psychol 2013; 18(1):12-23.

[2] Rees CS, Breen LJ, Cusack L, Hegney D. The contribution of individual psychological resilience in determining the professional quality of life of Australian nurses. Front Psychol 2015; 5(6):1-8.

[3] Hegney DG, Craigie M, Hemsworth D, Osseiran-Moisson R, Aoun S, Francis K, Drury V. Compassion satisfaction, compassion fatigue, anxiety, depression and stress in registered nurses in Australia: Study 1 results. J Nurs Manag 2014; 22(4):506-18.

[4] Thomas LJ. Revell SH. Resilience in nursing students: An integrative review. Nurse Educ Today 2016;36:457-462.

[5] Edward KI. The phenomenon of resilience in crisis care mental health clinicians. Int J Ment Health Nurs 2005;14:142-48.

[6] Garcia-Dia MJ, DiNapoli JM, Garcia-Ona L, Jakubowski R, O'Flaherty D. Concept Analysis: Resilience. Arch Psychiatr Nurs 2013; 27:264-70.

[7] Stephens TM. Nursing student resilience: A concept clarification. Nurs Forum 2013; 48(2): 125-33.

[8] Aroian KJ, Norris AE. Resilience, stress, and depression among Russian immigrants to Israel. West J Nurs Res 2000; 22(1):5467.

[9] Basım HN, Çetin F. Yetişkinler için psikolojik dayanıklılık ölçeği'nin güvenilirlik ve geçerlilik çalışması. Turk Psikiyatri Derg 2011; 22(2):104-14.

[10] Fitzpatrick JJ. Resilience. Arch Psychiatr Nurs 2009; 23(5):34142.

[11] Hart PL, Brannane JD, De Chesnay M. Resilience in nurses: An integrative review. J Nurs Manag 2014; 22: 720-34.

[12] Karaca A, Yıldııım N, Ankaralı H, Açıkgöz F, Akkuş D. Turkish Adaptation of Perceived Stress Scale, Bio-Psycho-Social Response, and Coping Behaviours of Stress Scales for Nursing Students. J Psy Nurs 2015; 6(1):15-25.

[13] Wilks SE, Spivey CA. Resilience in undergraduate social work students: social support and adjustment to academic stress. J Soc Work Educ 2010; 29(3):276-88.

[14] Goff AM. Stressors, academic performance, and learned resourcefulness in baccalaureate nursing students. Int J Nurs Educ Scholarsh 2011; 8(1): 1-20.
[15] Ardahan M. Sosyal destek ve hemşirelik. Atatürk Üniversitesi Hemşirelik Yüksekokulu Dergisi 2006; 9(2):68-75.(Turkish)

[16] Ruiller C, Van Der Heijden BI. Socio-emotional support in French hospitals: Effects on French nurses' and nurse aides' affective commitment. Appl Nurs Res 2016; 29:229-36.

[17] Güngörmüş K, Okanlı A, Kocabeyoğlu T. Factors influencing resilience in nursing students. J Psy Nurs 2015; 6(1):9-14.

[18] Hamdan-Mansour AM, Azzeghaiby SM, Alzoghaibi IN, Al Badawi TH, Nassar OS, Shaheen AM. Correlates of resilience among university students. AJNR 2014; 2(4): 74-79.

[19] Inci FH, Temel AB. The effect of the support program on the resilience of female family caregivers of stroke patients: Randomized controlled trial. Appl Nurs Res 2016; 32:233-40.

[20] Hartley MT. Examining the relationships between resilience, mental health, and academic persistence in undergraduate college students. J Am Coll Health 2011; 59(7):596-604.

[21] McGowan JE, Murray K. Exploring resilience in nursing and midwifery students: A literature review. J Adv Nurs 2016; 72(10):2272-83.

[22] 22.Reyes AT, Andrusyszyn MA, Iwasiw C, Forchuk C, BabenkoMould Y. Resilience in nursing education: An integrative review. J Nurs Educ 2015; 54(8):438-44.

[23] Karaca A, Yıldııım N, Ankaralı H, Açıkgöz F, Akkuş D. Hemşirelik Eğitimi Stres Ölçeğinin Türkçe' ye uyarlanması. Hemşirelikte Araştırma Geliştirme Dergisi 2014; 16(2):29-40. (Turkish)

[24] Eker D, Arkar H, Yaldız H. Factorial Structure, Validity, and Reliability of Revised Form of the Multidimensional Scale of Perceived Social Support. Turk Psikiyatri Derg, 2001; 12(1):1725.

[25] Thomas J, Jack BA, Jinks AM. Resilience to care: A systematic review and meta-synthesis of the qualitative literature concerning the experiences of student nurses in adult hospital settings in the UK. Nurse Educ Today 2012; 32:657-64.

[26] 26.Rios-Risques MI, García-Izquierdo M, Sabuco-Tebar EL, Carrillo-Garcia C, Martinez-Roche ME. An exploratory study of the relationship between resilience, academic burnout and psychological health in nursing students. Contemp Nurse 2016; 52(4):430-39.

[27] Smith GD, Yang F. Stress, resilience and psychological wellbeing in Chinese undergraduate nursing students. Nurse Educ Today 2017; 49:90-95.

[28] Hodges HF, Keeley AC, Troyan PJ. Professional resilience in baccalaureate - prepared acute care nurses: first steps. Nurs Educ Perspect 2008; 29(2):80-89.

[29] Luo Y, Wang H. Correlation research on psychological health impact on nursing students against stress, coping way and social support. Nurse Educ Today 2009; 29:5-8.

[30] Montes-Berges B, Augusto JM. Exploring the relationship between perceived emotional intelligence, coping, social support and mental health in nursing students. J Psychiatr and Ment Health Nurs 2007;14:163-71.

[31] Pines EW, Rauschhuber ML, Norgan GH, Cook JD, Canchola L, Richardson C, Jones ME. Stress resiliency, psychological empowerment and conflict management styles among baccalaureate nursing students. J Adv Nurs 2012; 68(7):148293.

[32] Ağaçdiken S, Bora NM, Özdelikara A. Hemşirelik öğrencilerinin hemşirelik eğitimine yönelik yaşadıkları stres düzeyinin belirlenmesi. Samsun Sağlık Bilimleri Dergisi 2016; 1(1):1-18. 
[33] Altıok HÖ, Üstün B. Hemşirelik öğrencilerinin stres kaynakları. Kuram ve Uygulamada Eğitim Bilimleri 2013; 13(2):747-66. (TurkisH)

[34] Yıldırım N, Karacan A, Ankaralı H, Açıkgöz, F, Akkuş D. Stress experienced by Turkish nursing students and related factors. Clin and Exp Health Sci 2016; 6(3):121-28.

[35] Burnard P, Edwards D, Bennett K, Thaibah H, Tothova V, Baldacchino D, Bara $P$,

[36] Mytevelli J. et al. . A comparative, longitudinal study of stress in student nurses in five countries: Albania, Brunei, the Czech
Republic, Malta and Wales. Nurse Educ Today 2008; 28(2):13445.

[37] Malkoç A, Yalçın I. Relationships among resilience, social support, coping, and psychological well-being among university students. TPCGJ 2015; 5 (43):35-43.

[38] Mayordomo-Rodríguez T, García-Massó X, Sales-Galán A, Meléndez-Moral JC, Serra-Añó P. Resilience patterns: Improving stress adaptation based on an individual's personal features. Int J Aging Hum Dev, 2015; 80(4):316-31. 